UDK: 821.134.2(83)-31 Фугет A.

821.112.2.09-31 Пленцдорф У.

DOI: https://doi.org/10.18485/legado_hispanico.2020.ch9

\author{
Ilinca Ilian ${ }^{1}$ \\ Universidad del Oeste de Timisoara \\ Rumanía
}

\title{
TRES NOVELAS DE ADOLESCENTES: SALINGER, PLENZDORF, FUGUET
}

\begin{abstract}
Resumen
El artículo se propone comentar la novela del chileno Alberto Fuguet Mala onda (1991) desde una perspectiva comparativa que patentiza su integración en la familia de novelas de adolescentes y más precisamente en el orden de aquellas obras que mantienen un diálogo intertextual con El guardián entre el centeno de J. D. Salinger. Para resaltar su especificidad dentro de este grupo, el libro será comparado, por una parte, con su prototipo norteamericano y, por otra parte, con una congénere alemana, la novela de Ulrich Plenzdorf, Die neue leiden des jungen W. (Las nuevas cuitas del joven W., 1972). Se recalcará de esta forma el ahondamiento del pesimismo e incluso del cinismo, así como la agudización de la conciencia política a lo largo de las décadas, rasgos unidos también a una separación sutil entre la perspectiva del narrador y del autor implícito en el marco de una común narración en primera persona. A través de estas tres novelas se puede observar la mutación de los valores y los ideales de vida en la sociedad occidental en la segunda mitad del siglo anterior.

Palabras clave: Novelas de adolescentes, literatura y política, J. D. Salinger, Ulrich Plenzdorf, Alberto Fuguet.
\end{abstract}

$\overline{{ }^{1} \text { ilincasn@gmail.com }}$ 
Aunque la adolescencia tiene una larga representación literaria, dado que la literatura occidental abunda en personajes con una edad comprendida entre los doce y los dieciocho años, el tema de la adolescencia aparece relativamente tarde. De hecho, la propia adolescencia en el sentido actual es una noción reciente, cuyo estudio empieza a principios del siglo XX con los trabajos del psicólogo Stanley Hall, que ubica esta etapa de la vida bajo el signo del «Sturm und Drang» y la designa como el periodo que corresponde desde el punto de vista ontogenético a lo que en el orden filogenético es el paso del hombre primitivo al hombre civilizado (Lerner \& Steinberg 2004: 47). Ulteriormente, los trabajos de Erik Erikson, Anna Freud y especialmente Jean Piaget difundieron la actual visión sobre la adolescencia como una etapa de transición, en que tienen lugar unas inmensas transformaciones cerebrales y el individuo emprende su primera gran búsqueda de la personalidad sobre el fondo de las tensiones contrastantes entre las normas familiales y las normas del grupo generacional. Dada pues la forja tardía del concepto, el nombre de «novelas de adolescentes» lo merecerían en puridad sólo las novelas escritas hacia mediados del siglo pasado y un lugar preeminente lo ocuparía El guardián entre el centeno de J. D. Salinger que, gracias a su excelencia, es una novela capaz de «crear a sus precursores», en el sentido de que a partir de ella se van a leer de forma distinta tanto las novelas románticas autoconfesivas, tipo Adolphe de Benjamin Constant, como las novelas de la gran modernidad protagonizadas por jóvenes artistas, como El retrato del artista adolescente de Joyce. En cuanto a sus sucesores, nos ocuparemos en este artículo de dos novelas escritas en la estela de la obra de Salinger, Die neue leiden des jungen W. (Las nuevas cuitas del joven $W$.) de Ulrich Plenzdorf (1972) y Mala onda de Alberto Fuguet (1991), intentando identificar las configuraciones dominantes del universo interior del adolescente en tres momentos distintos y en tres espacios que recibieron de manera diferente las influencias sociopolíticas y culturales típicas de la Guerra Fría. La principal razón de esta comparación consiste no solo en iluminar la influencia de Salinger en la conformación de un tipo específico de novela, protagonizada por unos adolescentes inadaptados, sino también en el estudio de la refracción de este modelo en dos novelas que declaran abiertamente esta filiación y la adaptan a unos contextos históricos y políticos totalmente diferentes. Al analizar las tres novelas y evidenciar sus similitudes estructurales, asistiremos, en el plano de la narración, a una degradación de los valores que vertebran la psique del joven hallado en la crisis identitaria y observaremos una pérdida paulatina de los ideales de origen romántico que se asocian con la 
edad juvenil. Tomamos pues estas tres novelas, que tienen un esquema narrativo común, el de la iniciación fracasada, como tantas ilustraciones artísticas de la mutación de los valores y los ideales de vida en la sociedad occidental en la segunda mitad del siglo anterior, resultado el más dañado el ideal de la pureza, que justamente figuraba antaño como rasgo definitorio de la primera juventud.

\section{Salinger: la obsesión por la pureza}

Vituperada, censurada, prohibida, reprobada o bien apreciada, gustada, querida, adorada, idolatrada, la única novela de J. D. Salinger El guardián entre el centeno es sin duda un hito en la novelística internacional y se puede ver como una novela de transición desde varios puntos de vista. De una parte, por su publicación en 1951, marca la transición de una etapa literaria a otra, pues hace el paso desde la brillante lost generation norteamericana (Fitzgerald, Steinbeck, Tom Wolfe y Hemingay) a una generación no menos atractiva para quienes la aprecien, la beat generation (Jack Kerouac, William Borroughs, Allen Ginsberg, Charles Bukowski). Vista desde la perspectiva de las transformaciones sufridas por la sociedad norteamericana, refleja el paso de la relativa unidad social creada por la participación norteamericana en la Segunda Guerra Mundial bajo la carismática presidencia de Franklin Roosevelt a una etapa mucho más problemática, la cual fue denominada por el sociólogo y etnopsícologo David Riesman la etapa de «la muchedumbre solitaria», según reza el título de su libro publicado en 1950, The Lonely Crowd. Se trata de una sociedad donde se da un cambio radical al «carácter social» con respecto al del siglo XIX (Riesman 1964: 1975) en el sentido de que, con los traumas de la guerra mal curados, la sociedad se aboca a un estilo de vida que aúna unas fobias tenaces, como la de la guerra atómica, unas intolerancias fuertes, como el anticomunismo mccarthiano y finalmente un consumismo que con el tiempo se agravará cada vez más. Por último, es la novela de Salinger una novela de transición por su tema, ya que presenta un caso de maduración más que dificultosa, casi imposible, lo que contrasta fuertemente con la tradición anterior de las novelas sobre la adolescencia que enfocaban el paso de la infancia a la madurez como un enriquecimiento obtenido a través de unas pruebas difíciles, sí, pero sumamente necesarias.

Aun dejando aparte las Bildungsroman clásicas, cuya dimensión educativa es central, se puede decir que incluso las grandes novelas de formación modernas suelen presentar la transición desde la infancia a la 
madurez como una iniciación lograda. El retrato del artista adolescente de James Joyce o Las tribulaciones del estudiante Törless de Musil o incluso, en parte, Lo que Maisie sabía de Henry James y también en parte En busca del tiempo perdido de Proust, presentan los desconciertos, extravíos y errores de los héroes como una etapa en que la impurificación moral se compensa por un avance en términos cognitivos y estéticos, lo que al final redundará en beneficio de la ética personal, pues se pasará de una estrecha visión tradicional a una moral basada en la creatividad, invención y descubrimiento auténtico. En cambio, el final de la odisea vivida por el joven Holden Caulfield es mucho más ambiguo: el héroe no encuentra una fórmula tan memorable como «silencio, exilio y astucia», por la cual Stephen Dedalus definirá su actuación por venir; tampoco proclama que «la verdadera vida es la literatura» como el narrador proustiano ni se convierte como Törless en «uno de esos seres de naturaleza estético intelectual» cuyo «interés personal, ese justo conocimiento de sí mismo, se concentra sólo [...] en el desarrollo del alma» (Musil 1985: 168-169). Cierto sector de la crítica considera de hecho que el héroe de Salinger queda hasta el final en una terca oposición ante la madurez. Así, su obsesión por preservar la pureza infantil se puede ver como un repliegue en una tierna edad idealizada, desde la perspectiva de la cual sólo se puede hacer una crítica de la sociedad, pero nunca se puede llegar a un diálogo y menos aún a una propuesta edificante.

Es cierto que una dimensión esencial de esta novela consiste en presentar sin ambages un caso de rebeldía absoluta, que desde este punto de vista, se emparenta con las novelas románticas de tendencia nihilista (Werther de Goethe, Hyperion de Hölderlin, Adolphe de Benjamin Constant, René de Chateaubriand etc.). Como sus antecesores románticos, el protagonista de Salinger abandona todos los asideros exteriores, que en su caso son principalmente la familia y el sistema educativo, pero también la religión institucionalizada y los incentivos comunes del tipo dinero y fama ${ }^{2}$. Sin embargo, a diferencia de sus antepasados románticos, no son las cuitas de amor las que provocan la crisis, aunque es cierto que un factor determinante en la decisión de Holden de abandonar el colegio Pencey Pen lo representa el asalto sensual de su compañero Stradler sobre Jane Gallagher, a quien Holden adora de forma casta. De hecho, el

\footnotetext{
${ }^{2}$ Con respecto a la desconfianza en el cristianismo institucionalizado, dice el narrador en el capítulo 14: «Nunca puedo rezar cuando quiero. En primer lugar porque soy un poco ateo. Jesucristo me cae bien, pero con el resto de la Biblia no puedo. Esos discípulos, por ejemplo. Si quieren que les diga la verdad no les tengo ninguna simpatía» (Salinger 1995: 66). El desprecio por el dinero y la fama se desprende del desacuerdo de Holden con su hermano B.D. que «prostituye» su gran talento literario por escribir guiones en Hollywood.
} 
tema de la pureza humillada o en peligro de profanarse es prácticamente el distintivo del protagonista salingeriano $y$, a pesar de sus experiencias con los vicios y la violencia, Holden tiende de forma natural a la pureza y candidez. Es lo que explica su especial devoción por los niños y el inmenso amor que profesa por su hermana menor Phoebe y por su joven hermano muerto a los doce años, Allie. La naturalidad de los niños, su belleza moral innata, es lo único que Holden considera valioso y es por eso que su único sueño consiste en convertirse en el protector de la pureza infantil, según reza uno de los fragmentos más célebres y citados del libro:

Muchas veces me imagino que hay un montón de niños jugando en un campo de centeno. Miles de niños. Y están solos, quiero decir que no hay nadie mayor vigilándolos. Sólo yo. Estoy al borde de un precipicio y mi trabajo consiste en evitar que los niños caigan a él. En cuanto empiezan a correr sin mirar adónde van, yo salgo de donde esté y los cojo. Eso es lo que me gustaría hacer todo el tiempo. Vigilarlos. Yo sería el guardián entre el centeno. Te parecerá una tontería, pero es lo único que de verdad me gustaría hacer. Sé que es una locura (Salinger 1995: 112).

No obstante, la inocencia conservada artificialmente se transforma en una forma muy rara de perversión, y uno de los errores de Holden consiste precisamente en rechazar la madurez, vista como inevitablemente asociada con la impurificación ${ }^{3}$. A poca distancia de la publicación del libro de Salinger, esta idealización de la infancia iba a convertirse en un elemento central de la contracultura norteamericana de los años sesenta y no sorprende que los beatniks tamaran a Holden como modelo de rebeldía radical en nombre de la autenticidad y de la pureza sin tacha ${ }^{4}$. Lo

\footnotetext{
${ }^{3}$ El autor implícito sugiere de forma sutil que la metáfora personal de Holden, que da título a la novela, proviene de una mala interpretación dada a unos versos de Robert Burns. Al presentar ante su hermana Phoebe su sueño de vigilar a los niños eternamente, la niña le señala que los versos originales no son «Si un cuerpo coge a otro cuerpo cuando van entre el centeno» (if a body catch a body coming through the rye) sino «Si un cuerpo encuentra a otro cuerpo cuando van entre el centeno» (if a body meet a body coming through the rye) (Salinger 2018: 113). Por un lado, Holden se desentiende del significado erótico claramente resaltado en el poema original y por otro lado reemplaza la idea del encuentro entre dos personas de estatuto igual con su propia obsesión relacionada con el cuidado y la protección de los desvalidos. Señala un destacado crítico de Salinger: «Ironically, the words are changed to indicate an action to be stopped, the plummeting over the edge of the cliff. Holden plans to protect innocence and live in an ideal world. But Robert Burns talks about change - meeting a person, daring to seize the moment, and having an intimate encounter with someone» (Haugrud Reiff 2008: 72).

${ }^{4}$ Se sabe, de hecho, que Salinger fue un autor de culto para los beats y que el promotor de este movimiento literario, Jack Kerouac, veneraba al padre literario de Holden. En cambio,
} 
que falta en la interpretación beat de esta novela es la ironía y la distancia. Es ilustrativa en este sentido la opinión de un crítico más lúcido, Richard Stayton, que manifiesta su admiración constante por esta gran novela, pero advierte que si en la adolescencia la amaba porque «validaba la inadaptación», en la edad madura la aprecia porque ve en Holden un esnob entre otros, un esnob que es capaz no obstante de cuestionar el repudio de la madurez (Stayton 1985: 35). De hecho, los críticos suelen concordar en que la crítica del esnobismo y cursilería a la cual se entrega incesantemente Holden no le protege para nada de caer él mismo en los mismos defectos reprobados (Miller 1982; Lee 1990). Al recelar a tal punto lo que él llama, con una palabra que se repite obsesivamente, phony (falso, hipócrita, cursi), Caufield está siempre en peligro de convertir la autenticidad en un privilegio para una selecta minoría y de transformarse así en un esnob.

La grandeza de la novela de Salinger proviene de la capacidad del autor de evitar precisamente las trampas de la facilidad, los dualismos brutales o las conclusiones terminantes. De hecho, el arte de Salinger es un arte alusivo, cuya sutileza contrasta fuertemente con la verbosidad del confuso adolescente que huye del colegio y vagabundea por Manhattan obsesionado por los patos del Central Park. Es por eso que el final de la novela queda decididamente ambiguo y admite una rica gama de interpretaciones, desde las más pesimistas, que enfatizan la incapacidad de Caulfield para madurar, debido al trauma sufrido en la pubertad, cuando murió su hermano (E. W. Miller, 1982), hasta las más optimistas, que lo ven como un joven capaz de salvarse por la escritura y por el amor hacia los seres humanos (Robert Lee, 1990). Se puede observar que esta última interpretación emparenta a Holden con los protagonistas adolescentes de los grandes modernos Joyce, Proust, Musil, mientras que la primera lo acerca más a los héroes románticos que, como ha señalado un

en Seymour: una introducción Salinger se dirigió directamente al autor de On the road para manifestar su total desavenencia con los «vagabundos del dharma, los fabricantes de filtros de cigarrillos para los hombres que piensan, los beats, los andrajosos y los iracundos, los creyentes elegidos, todos los expertos soberbios que saben tan bien lo que deberíamos o no deberíamos hacer con nuestros pobres y pequeños órganos sexuales, todos los muchachos barbudos, orgullosos, ignorantes, todos los guitarristas aficionados y los asesinos zen, y los estetizantes rockers unidos que contemplan por encima de sus ignaras narices este espléndido planeta» (Salinger 1990: 101-102). Es de hecho sintomático el hecho de que, si bien tanto Salinger como Kerouac eran escritores que despreciaban la fama y veían la escritura como un testimonio de una búsqueda espiritual, Salinger llegó a callarse por completo en 1963, aislándose del mundo y entregándose por completo a las prácticas de disciplina interior y ascesis, mientras que Kerouac se dejó caer en el alcoholismo, lo que le provocó una muerte prematura en 1969. 
investigador, sufren de una depresión con raíces en una infancia marcada por la «deprivación» maternal, lo que explica su inestabilidad síquica y la dificultad de establecer vínculos íntimos y sólidos con nadie (Pasco 1997: 35). De las propuestas de lecturas más perspicaces se puede destacar la de Denis McCort que considera que en esta novela ya existe una referencia explícita al budismo Zen, a cuyos principios el autor empezó a acercarse a mediados de los años cuarenta: así la obsesión de Holden por los patos se relaciona con un koan citado por Daisetsu Teitaru Suzuki y que se refiere precisamente al tema profundo que preocupa a Holden, esto es la relación entre el cambio y la permanencia, lo que se traduce en la capacidad de vivir al mismo tiempo como niño y como adulto ${ }^{5}$.

\section{Plenzdorf: el accidente}

La indudable calidad artística de la novela de Salinger la salvó del peligro de sucumbir ante su propia fama y más aún cuando estuvo implicada en asuntos dudosos, como por ejemplo la pasión obsesiva que profesaba por ella el asesino de John Lennon, o bien el misterio del retiro de su autor en 1963. Por otra parte, la descendencia estrictamente literaria de esta obra es notable y, en calidad de paratexto, la novela de Salinger hace patente algunos de sus rasgos estructurales básicos: narrador adolescente en primera persona, fuga del medio protector (familia, escuela), relación distante o tensa con los adultos en general y con los padres en especial, perfil psicológico caracterizado por la inadaptación, hipersensibilidad etc. Muchos de estos rasgos se encuentran en la novela Las nuevas cuitas de $W$. de Ulrich Plenzdorf (1933-2007), autor alemán que alcanzó una gran reputación en la antigua Alemania democrática como guionista, dramaturgo y prosista y cuya obra más célebre fuera del espacio alemán es la mencionada novela, publicada en 1972/19736. Para la historia literaria alemana, el libro es importante porque fue prácticamente el primer libro

\footnotetext{
${ }^{5}$ El mismo crítico lee la última imagen del libro, con Holden contemplando a su hermana Phoebe girando en el tiovivo de Central Park, como una alusión al poema de Rilke Das Karussell en que el poeta, conforme a la tradición romántica, aparece como un ser capaz de mantener vivo al niño interior y por lo tanto apto para comprender a la vez la perspectiva mágica del niño y la visión lúcida del adulto (Denis McCort 1997).

${ }^{6}$ Prácticamente existen cuatro versiones de la obra de Plenzdorf: por un lado, el guión cinematográfico inicial, que fue censurado en 1968 y que se realizó en 1975 en la República Federativa Alemana; por otra parte, existe la versión en prosa publicada en 1972 por la revista de literatura Sinn und Form; el mismo año se estrena la obra teatral con el mismo título; la novela, con modificaciones importantes con respecto al texto publicado en la revista, aparece en 1973.
} 
de gran éxito de público en la corta etapa de apertura cultural acaecida en los primeros años de presidencia de Erich Honecker, entre 1971 y 1976, y en esta calidad la novela de Plenzdorf encarna la transición desde una poética anquilosada en los clisés socialistas a una expresión verbal libre y natural, que iba a reconectar la literatura de la Alemania democrática con la gran tradición literaria de este espacio cultural, y especialmente con el legado romántico ${ }^{7}$.

Aunque el diálogo intertextual explícito se desarrolla con la obra de Goethe aludida en el título, la aventura del protagonista llamado Edgar Wibeau tiene similitudes evidentes con la de Holden, que además es uno de los dos héroes literarios favoritos del protagonista alemán. Como su modelo, Edgar huye a los diecisiete años del colegio técnico donde estudia, abandona el hogar familiar y, liberado de los lazos sociales, consigue tener una perspectiva más lúcida y, en muchos aspectos, muy crítica sobre su circunstancia. Una diferencia de peso desde el punto de vista narrativo consiste en que la voz del narrador proviene del más allá. Así, la narración del joven se entrelaza con las evocaciones que hacen sobre él sus allegados, gracias a las cuales se descubren los pasos de las últimas semanas de vida del adolescente: la fuga de su ciudad natal Mittenberg, su instalación en Berlín en un quiosco abandonado que espera una inminente demolición, el intento fracasado de entrar en la academia de artes plásticas, el enamoramiento de una chica un poco mayor que él, además comprometida, la incorporación en un equipo de pintores industriales y finalmente la tentativa de construir un aparato eléctrico sin tener los utensilios necesarios, lo que lo lleva a la muerte.

El que provoca las mencionadas evocaciones es el propio padre de Edgar, que lo había abandonado en su tierna infancia y que, al entrevistar a la gente que lo conoció, procura aprender algo sobre su hijo cuando ya es, de todas formas, muy tarde. Al final el padre se declara vencido, porque

\footnotetext{
${ }^{7}$ Es evidente que la recepción de la obra de Plenzdorf fue totalmente distinta, por una parte, en el espacio de procedencia, donde encarnó una ruptura con el realismosocialista, y, por otra parte, en el mundo literario de la República Federal de Alemania, en que los críticos señalaron, al contrario, la fuerte impronta del optimismo y salud moral promovidos a través del aparato ideológico. Así, el protagonista Edgar les parece, más allá de su rebelión adolescente, una encarnación del hombre ideal de la RDA (Marcel Reich-Ranicki apud Jäger 1984: 50) y la obra es juzgada como un producto ingenioso, «con gente buena que tiene pequeñas imperfecciones» (Joaquin Kaiser apud Jäger 1984: 51) si no se ve censurada como un rotundo «kitsch» (Karena Nichoff apud Jäger 1984: 51). Un comentador más objetivo puede criticar a su vez a los propios críticos la falta tanto de sutileza política como de refinamiento literario, ya que los mencionados críticos de la RFA no detectaron el vínculo con la herencia literaria alemana (Jaëger 1984: 50) y por ende se quedaron en un mero análisis ideológico.
} 
la búsqueda lo ha llevado sólo a descubrir unas pistas que no lo llevan lejos: «No volví a ver a Edgar desde que tenía cinco años. No sé nada sobre él, ni siquiera ahora. ¡Charlie, una barraca del jardín derribada, cuadros que ya no existen, y la máquina esa» (Plenzdorf 1984: 109 y última). El lector, en cambio, tiene la ventaja de unificar estos enfoques, adhiriéndose inevitablemente a la perspectiva del narrador, que además, justo como Holden, resulta un ser entrañable por su naturalidad, desenvoltura y total carencia de resentimientos y amargura.

Ellenguajeestá,como en el casodeSalinger,lleno degiros adolescentes, lo que de hecho tuvo una contribución esencial al éxito de la obra en un espacio como el de la República Democrática Alemana a principios de los años setenta. No hay, en cambio, palabrotas ni experiencias con el alcohol o tabaco y, a diferencia de Holden, Edgar tiene una perspectiva mucho más relajada acerca de las relaciones con el sexo opuesto. Comenta así Edgar su pasión por el libro y el personaje de Salinger:

Mis dos libros favoritos eran: Robinson Crusoe. [...] El otro era el de Salinger ese. Había caído en mis garras por pura casualidad. Nadie lo conocía. Es decir, nadie me lo había recomendado y tal. Mejor, porque entonces no lo habría ni tocado. [...] A pesar de todo, aún ahora me pongo malo si pienso que ese libro podría no haber caído nunca en mis manos. El tal Salinger es un tío con clase. Eso de que anduviera dando vueltas por ahí, por Nueva York, bajo la lluvia y sin poder ir a casa por haberse largado de la escuela aquella, donde, de todos modos, se lo iban a cepillar, era algo que me enrollaba cantidad. Si hubiera sabido su dirección, le habría escrito diciéndole que se viniera para acá. Debía de tener justo mi edad. Claro que Mittenberg era un pueblucho comparado con Nueva York, pero seguro que aquí se hubiera recuperado de maravilla. Sobre todo, le hubiéramos eliminado sus estúpidos problemas sexuales. Eso es quizás lo único que nunca he entendido en Salinger (Plenzdorf 1984: 27).

La identificación del autor con el narrador protagonista y la omisión de la distancia temporal y de las diferencias de planos ontológicos evidencian claramente la cercanía que siente Edgar con respecto al personaje de Salinger. Distinta relación es la que tiene con el Werther goetheano, cuyo destino ficticio llega a emular sin querer. Si bien, como en la novela goetheana, se enamora de una mujer comprometida y luego casada y también, como Werther, muere al final, la actitud respecto al héroe romántico es siempre irónica y distante.

Primero, a diferencia de la sensación de cercanía y amistad que le despierta Salinger / Holden, el personaje goetheano le parece desde el 
principio un «idiota» que se suicida porque no puede tener a la mujer amada, en vez de actuar de acuerdo con sus deseos:

A no ser que estuviera completamente idiotizado, tendría que haberse dado cuenta de que ella sólo estaba esperando a que él hiciera algo, la Charlotte esa [...] ¿Y qué es lo que hace? Se queda mirando tranquilamente cómo se casa ella. Y luego se quita de en medio (Plenzdorf 1984: 29) ${ }^{8}$.

\section{Luego, de nuevo en claro contraste con la novela de Salinger, el} estilo del libro le parece totalmente artificial:

Aquello no tenía nada de real. Pura basura. Y encima el estilo aquel. Que no estaba más que plagado de corazón y alma, y felicidad. No me puedo imaginar que nadie hablara así, ni siquiera hace tres siglos. [....] El que lo ha escrito debería leerse alguna vez a mi Salinger. ¡Eso sí que es auténtico, tíos! (Plenzdorf 1984: 30).

En tercer lugar y de modo muy cómico, Edgar ignora por completo al autor de Werther y por ende su dimensión cultural, simplemente porque

\footnotetext{
${ }^{8}$ La diferencia entre Werther y el «nuevo W.» se ilustra perfectamente en la actitud ante el amor y el sexo. La nueva Charlotte, a quien el joven del siglo XX llama de modo sugerente Charlie, es, de forma poco sorprendente, más provocadora que su modelo romántico y, en un momento de furia provocada por la rigidez de su antiguo novio y actual esposo, atrae a Edgar a una única e indeterminada aventura sensual, que, vivida bajo una fuerte lluvia, hace eco al momento de máximo acercamiento entre los héroes goetheanos. Se trata de la noche en que, al contemplar desde la ventana, en compañía de Werther, una gran tormenta, la mujer pronuncia el nombre del poeta favorito de los dos, Klopstock, declarando así de forma más o menos consciente la profunda afinidad entre sus dos almas:

¡Carlota había apoyado los codos en el marco de la ventana y miraba hacia la campiña, luego levantó los ojos al cielo; después los fijó en mí y vi que los tenía cuajados de lágrimas; por fin, puso su mano sobre la mía y exclamó: «jOh Klopstock!». Abismado en un torrente de emociones que esta sola palabra despertó en mi espíritu, recordé al instante la oda sublime que ocupaba a la sazón el pensamiento de Carlota. No pude resistir: me incliné sobre su mano, se la llené de besos y lágrimas de placer y volvieron mis ojos a encontrarse con los suyos. ¡ Oh insigne poeta! Esta sola mirada, que debías haber visto, basta para tu apoteosis (Goethe 1997: 51).

El contraste entre, por una parte, la unión de las almas por la mediación de la contemplación estética y, por otra parte, la unión de los cuerpos durante la tormenta, o sea en un ambiente natural asociado con el romanticismo, es una eficaz fuente de comicidad. Este efecto cómico no sólo chocaba a los lectores en una época dominada por el puritanismo socialista, sino que igual se celebraba en los propios años setenta como una victoria de la risa frente a la solemnidad burguesa (Neubert 1973: 135). Además, este juego intertextual humorístico es también una prueba de que durante el respectivo período de deshielo ideológico se consideraba como sumamente aceptable la parodia de los clásicos.
} 
había encontrado el libro en un retrete, de noche, y había empleado las portadas y las últimas páginas en que figuraba el epílogo crítico para necesidades mucho más terrenales ${ }^{9}$.

Con todo eso, a lo mejor precisamente por causa del efecto de distanciamiento que le produce el libro romántico, Edgar se servirá de los fragmentos goetheanos para comunicar con su medio: a través de las citas goetheanas le da informaciones sobre su vida a su amigo Willi (tocayo, como se ve, del destinatario de las cartas de Werther); emplea ciertos fragmentos para fustigar la estulticia, la rigidez o la autosuficiencia de ciertos representantes del sistema, usando así el texto clásico a modo de arma contra las agresiones morales de su medio social. Edgar, por tanto, rechaza lo que el paso del tiempo ha marchitado del prototipo romántico primerizo y si bien se ríe de la hipersensibilidad narcísica de Werther, no abandona sin embargo el espíritu romántico, cuya encarnación actualizada la encuentra en el entrañable Holden y que, como tal, sigue representando para él un modelo viable. Es pues de destacar la similitud del personaje de Pletzdorf con el modelo norteamericano, que por su afán de pureza, tendencia a la rebeldía y resistencia al materialismo y artificialidad, corresponde a un tipo de neorromanticismo muy presente en la atmósfera de la Guerra Fría, con independencia del bloque ideológico en el que se vive y se crea ${ }^{10}$.

Por fin, se puede observar que mientras que en el caso de la novela de Salinger, la transición de la infancia a la madurez tenía un desenlace ambiguo, en su descendiente alemana se trata un proceso interrumpido brutalmente, por causa de un accidente que de cierta forma anula la entera progresión del héroe en busca de su autorrealización. Las memorias de ultratumba comunicadas por el joven conservan no obstante el tono desenvuelto, vital y burlón que, al parecer, caracterizan al adolescente vivo y el diálogo que mantiene el narrador con los personajes que lo

\footnotetext{
${ }^{9}$ Los críticos han destacado la ironía con tintes rabelaisianos de esta situación y asimismo el fino ataque sobre las prácticas educativas y culturales del socialismo, especialmente en lo que respecta al culto museístico a los clásicos alemanes en la antigua RDA y la costumbre de acompañar los libros con un epílogo crítico destinado a orientar la lectura en conformidad con la ideología del partido (Waiblinger 1976: 78).

${ }^{10}$ Es sugerente, en este orden de ideas, la descripción del universo salingeriano que hace el escritor EL Doctorow con ocasión de la muerte del autor de El guardián entre el centeno en 2010: «The Glasses and their children - Franny, Zooey, Seymour, Buddy and the rest [...] of course they were too perfect, with all their sensitivities, their Buddhism, their philosophical despair and their family bondings, but that's why we responded as we did. These were the cold war years and the self-involved siblings were models of romantic alienation» (Doctorow 2010).
} 
evocan destaca por su total carencia de amargura y desesperación. A pesar del título goetheano, Wibeau es pues lo más alejado al héroe romántico nihilista y suicidario y, si el libro no termina bien, eso no se debe a la inclinación enfermiza del protagonista, sino al accidente, que se puede entender como una alusión velada al 'accidente histórico' que le toca vivir a un alemán atrapado en el bloque socialista durante la Guerra Fría.

\section{Fuguet: el cinismo}

Otra por completo es la posición de Matías Vicuña, el protagonista de Mala onda de Alberto Fuguet, con respecto al modelo salingeriano en particular y a la línea de las novelas de adolescentes en general. Claro, la novela de Fuguet comparte con el prototipo norteamericano y su congénere alemana una serie de rasgos especificados anteriormente: narración en primera persona, trama que incluye la fuga de casa y del colegio, dificultades de relacionarse con los adultos y con sus prójimos en general etc. No obstante, a diferencia de Holden de Salinger y de Edgar de Plenzdorf, en el caso de Matías de Fuguet su virtual apetencia por la pureza se ve constantemente contrarrestada por un estilo de vida caracterizado por la superabundancia material, que facilita y banaliza el consumo de las drogas, el alcohol y la sexualidad desenfrenada. Matías es el típico hijo consentido de una familia perteneciente a una oligarquía corrupta y cínica que el régimen de Pinochet protege bajo el pretexto de apoyar a la clase de los emprendedores neoliberales que atraen riqueza al país. En este caso, la lucha contra el materialismo, la afectación o el esnobismo, que son la marca de los adolescentes a lo Holden, se enmaraña en una confusión mucho mayor de lo que se pueden imaginar sus antecesores ficcionales.

Los críticos han hecho la justa observación de que, al situar la acción de la novela en la semana anterior al plebiscito organizado por el dictador a fin de aprobar la constitución del Estado, la aventura de Matías refleja fielmente la trayectoria de la entera sociedad chilena (Rojo 2011: 183). El voto a favor o en contra de la constitución de 1980 se traduce, en el caso del personaje, en su decisión de seguir en su medio familiar o de abandonarlo con valentía. El paralelismo es llamativo: las posibilidades de derribar el régimen militar eran casi nulas, ya que el plebiscito organizado el 11 de septiembre de 1980 fue una acción destinada a salvar unas apariencias de democracia que nadie podía tomar en serio, puesto que con la nueva constitución se pretendía legalizar lo que la dictadura ya había cometido en los últimos siete años. Análogamente, las probabilidades que tiene 
Matías de poder salir de su mundo son mínimas, dado que, a pesar de su inteligencia y capacidad de razonamiento crítico, la influencia de los representantes del Sí (los conformistas) es mucho mayor que la de los representantes del No (los rebeldes). El grupo de los primeros lo constituye la entera familia, con padres, abuelos, hermanas y la parentela política, así como la mayoría de sus camaradas de colegio, mientras que los contestatarios están representados por unos personajes tan variados como la profesora de castellano Flora Montenegro, la indócil ex camarada Ximena Santander, la empleada de la casa Carmen y finalmente el barman Alejandro Paz. No deja de ser ilustrativo el hecho de que la resultante de toda esta influencia subversiva se materialice en la figura de Holden Caulfield, con quien Matías toma por fin contacto después de haber pospuesto varias semanas la lectura del libro recomendado por Alejandro Paz.

Es bajo el efecto de la fascinación que le produce el personaje salingeriano cuando Matías tiene un arrebato de verdadera rebeldía contra su familia y se va de la casa, no antes de sustraer de la cartera de su padre un cheque en blanco, así como una buena dosis de cocaína. La rebelión tiene no obstante una fuerte marca de inautenticidad, ya que más que un encuentro capaz de provocar el distanciamiento y el reconocimiento de sí mismo, se trata de una posesión, que tiene algo diabólico: «Es como si Holden Caulfield se hubiera posesionado enteramente de mí. Como en El exorcista: el diablo se ha apoderado de mi mente» (Fuguet 2011: 261). El efecto que tiene Holden, de hecho, no difiere mucho de los otros estímulos con los que está acostumbrado: «[Holden] es más un ejemplo a seguir, un apoyo, un golpecito en la espalda. Es como un trago. 0 una línea de coca. Pero igual es peligroso. Igual me asusta» (Fuguet 2011: 262). El grado de inautenticidad de esta experiencia lo percibe, de hecho, el propio protagonista cuando, al tomar un taxi, se sorprende de estar a punto de entablar una conversación típicamente salingeriana con el chófer:

Cuando casi le pregunté que creía él que ocurría con los patos cuando el lago se congelaba en invierno, me di cuenta de que estaba en serios problemas y que quizás no debí leer The Catcher in the Rye después de haber regresado, borracho y deprimido, del horroroso cumpleaños de Rosita Baros. Por suerte no abrí la boca; no hubiera sabido cómo explicarle, ya que el único lago con patos que conozco -laguna más bien- está en el Parque O'Higgins y, como bien advirtió la concha de su madre del Nacho, en Santiago no nieva (Fuguet 2011: 262). 
El libro de Fuguet se puede leer de forma más tradicional y así la tentativa de Matías de autodefinirse se entiende como un lento despojamientos de las imágenes que los demás proyectan sobre él, a fin de encontrarse a sí mismo. Es la interpretación dada por María Nieves Alonso que prueba que la novela conserva las pautas de las novelas de formación, aunque en este caso «asistimos a una (in)versión, (per)versión y (re)visión de los relatos de aprendizaje tradicionales y válidos como tales» (Nieves Alonso 2004: 11). La mencionada autora considera que los dotes, la cultura y el perfil psicológico de Matías lo hacen apto para poder salvarse de veras, principalmente a través de la escritura, ya que esta narración en primera persona, con raros pasajes de relato en segunda persona, se puede leer (y es la opción de Nieves Alonso) como un diario íntimo, lo que puede anunciar a un escritor en ciernes. La salvación por medio del arte (que el texto, de hecho, ni valida ni invalida) emparenta a Matías con los adolescentes-artistas modernos, pero no anula la defección moral que marca la adolescencia del protagonista.

Una lectura que consideramos más acertada enfatiza el parecido de Matías Vicuña con la larga serie de personajes occidentales que sufren la grave enfermedad melancólica (Rojo 2011: 188), lo que de hecho está confirmado por un gran número de citas ilustrativas de la novela de Fuguet:

Tempranísimo. Demasiado tarde. No hay nada que hacer. Te has quedado fuera. No sabes qué esta ocurriendo, cuáles son los planes, qué mierda han preparado los elegidos esta noche. Fiestas, reuniones, hotdogparties, orgías, garitas de poker. Lata, lata, lata (Fuguet 2011: 73)

Sigo aburrido, lateado. Incluso pensar me agota. Esto lo tengo más que asumido y me preocupa. Pensamiento que me ataca, conversación en la que me enfrasco, opinión que escucho, párrafo que leo, todo me da lo mismo, todo me agobia, es angustiante y me molesta. Estoy aburrido, apestado. No me atrevo a pensar. Pensar me da ideas. Cierro los ojos para absorber los rayos del sol (111)

- Qué lata.

- Sí, cualquier lata.

- ¿Y por qué fuiste entonces?

- Uno no siempre sabe lo que hace.

- Uno intenta siempre, Matías.

- Ni la perfección ni la madurez está entre mis metas.

- Se nota. (158) 
- Estoy aburrido de perder, Flora - le digo.

- Entonces, intenta crecer.

- No sé si sea ésa la solución (173)

A diferencia de su congénere alemán, Matías sufre pues realmente de un complejo wertheriano, que apacigua con las drogas y el alcohol; a diferencia del personaje salingeriano, sabe que la apuesta por la inocencia está destinada de antemano al fracaso y opta así por la inmadurez e imperfección propias de una edad de transición como la adolescencia.

Por otra parte, Matías se encuentra en otra etapa histórica y en un medio político-cultural en que las ansias de pureza de Holden ya no resisten ante los complejos retos lanzados por una sociedad que ha perdido por completo la capacidad de distinguir entre lo moral y lo inmoral, entre lo auténtico y lo inauténtico. Si en Holden quedaban unos últimos destellos del nihilismo romántico de la excepción, que se reflejaba en su actitud de superioridad frente a los phoneys o 'inauténticos', en Matías estamos ante el nihilismo moderno del Das Man, que se traduce en el desengaño, la apatía y, al fin y al cabo, el conformismo.

De hecho, la rebelión vivida bajo la influencia del personaje salingeriano no dura más que un día: el orden paterno, profundamente corrupto, vuelve a atraparlo, enganchándolo con los alicientes más fáciles, el sexo y la droga. La reconciliación entre el joven rebelde y el padre da lugar a una de las escenas más sórdidas de la literatura, en que el hijo y el padre practican sexo pagado intercambiando parejas y drogándose juntos al lado de dos prostitutas en uno de los locales discretos y ultraprivados reservados a los oligarcas pinochetistas. Entre dos partidas de sexo, el adolescente ebrio y drogado encuentra en uno de los pasillos de este local un poster con una panorámica nocturna de los rascacielos de Manhattan: «Salgo al pasillo empapelado de negro y avanzo hasta el living, donde hay una minifuente de agua y un poster inmenso, que ocupa una pared entera, con una panorámica nocturna de los rascacielos de Manhattan» (Fuguet 2011: 230). La función de este póster en el texto es, evidentemente, la de representar un un recordatorio de Holden y todo lo que simbolizaba él para Matías; sin embargo, la reacción del jóven ante esta imagen es nula, lo que indica claramente su grado de obnubilación y por lo tanto la superficialidad de su pasajera identificación con el idealista personaje de Salinger.

Al procurar dar con una característica básica del estilo de McOndo, un crítico afirma que en estos textos «[a]ntes que una sintaxis narrativa, se lee una parataxis narrativa: a partir de una situación de partida, pequeños 
fragmentos narrativos se independizan del devenir temporal, pudiendo, de hecho, suceder en un orden diferente al que despliega el texto» (Rosso apud Nemrava \& Rosso 2014: 87). La máxima debilitación del nexo causal y el efecto más acumulativo que progresivo del relato hacen que «estas narraciones no concluy[a]n, sino sólo termin[e]n» (Rosso apud Nemrava \& Rosso 2014: 119). Si las cosas se presentan de esta forma, se puede decir que la fuga de casa de Matías, su deambular nocturno por los barrios peligrosos de Santiago, el alojamiento en el hotel Central y todas sus acciones durante su escapada no son, de hecho, la consecuencia de las anteriores experiencias del joven, sino que este episodio es más bien una secuencia entre otras, que se sucede en el mismo plano intranscendente en que tiene lugar todas las falsas rebeldías de Matías. Este 'happening' en que Vicuña juega a ser Holden, imitándole desde la lúdica mitomanía hasta el uso de su famoso gorro rojo de cazador, se inserta así en una larga lista de pasatiempos, que incluyen borracheras, reuniones con drogas, aventuras sensuales más bien sórdidas, pero también intentos de llegar a una comunicación sincera con algunos amigos, con la chica cortejada y con la profesora preferida.

Es sugerente que en el caso del personaje de Plenzdorf el padre, aunque ausente, sigue representando para el joven una figura digna de admiración y, en esta calidad, contrasta totalmente con una madre conformista e inauténtica. Edgar, de hecho, visita de incognito a su padre y no sale decepcionado después de este encuentro; al contrario, el hecho de hallarlo vestido de jeans y en compañía de una bella mujer le confirma que su padre rechaza el estilo de vida uniformado que promueven los dirigentes socialistas. La rebelión de Edgar es, pues, un intento de reconectarse con el orden paterno que encarna la oposición a la ética colectivista del socialismo, indiferente a las necesidades reales del individuo.

En el caso de Mala onda, estamos en un mundo en que el orden paterno, igual que el materno, están tan deteriorados que cualquier intento de entender la realidad con su ayuda está condenado al fracaso. La corrupción afecta los ideales antaño más valiosos, en este caso la propia idea de salvación. Es sugerente que el último monólogo de la novela tiene una tonalidad victoriosa y se presenta como una prueba pasada con éxito: «Sobreviví, concluyó. Me salvé. Por ahora» (Fuguet 2011: 291 y última). No sólo estamos en un mundo al revés, en que la elección de la miseria moral se toma por un acto de valentía y decisión, sino que se nos presenta un universo percibido como una transición continua, que no admite las posturas definitivas y donde la adolescencia, con su inconformismo y 
su irresponsabilidad, se ha convertido en el ideal humano. Se trata pues de un mundo en que el consumo satisface al final todas las necesidades, embotando así las ansias de crecer y perfeccionarse y negando así a la sociedad toda posibilidad de transformación verdadera.

Publicada en 1991, en la etapa de transición hacia la democracia después de la dictadura de Pinochet, la novela de Fuguet narra una historia de cobardía y defección moral ocurrida once años antes, en 1980. El grado de optimismo del narrador con respecto a una posible 'salvación' dentro de una sociedad dominada por el consumismo y la ética del no cambio es, como se ve, bastante reducido, por no decir inexistente.

\section{Conclusiones}

Las tres novelas con protagonistas adolescentes analizadas reflejan otras tantas sociedades y relaciones entre individuos y generaciones durante la Guerra Fría, en tres espacios que recibieron de forma completamente distinta la influencia de esta tensión internacional que marcó la segunda mitad del siglo anterior. Sería arriesgado afirmar que la evolución, o mejor dicho involución, del perfil moral del protagonista revela la degradación de los valores sociales bajo la influencia cada vez más acusada de un estilo de vida consumista, en cambio es innegable que en esta transformación de la imagen del adolescente se encuentra una evidente inseguridad con respecto al ideal de vida perseguido. Así, se puede observar un paralelismo muy elocuente con las novelas románticas de tendencia nihilista, del tipo Adolphe de Benjamin Constant. Asimismo, es posible medir la diferencia con respecto a las novelas de adolescentes artistas de principios del siglo XX (Joyce, Proust, Musil) y observar que la salvación a través del arte, sin desaparecer por completo, deja de ser vista como vía principal de autorrealización. El final ambiguo de la prueba a la que se somete el personaje de Salinger no se resuelve de forma positiva, pero deja abierta una posible salvación «espiritual» que intenta unir lo transitorio con la permanencia, como en un koan zen ininteligible con la razón instrumental; en el caso de su émulo demócrata alemán se puede entrever una posible alternativa más luminosa si no hubiera intervenido el «accidente» banal, pero trágico, que igual podría leerse como el «accidente histórico» del paréntesis totalitario del bloque socialista en Europa del Este. No obstante, en el caso del protagonista de Mala onda se remarca, al contrario, la capacidad de pactar con una forma de alienación, falsedad y autoengaño, o lo que es lo mismo con adoptar un comportamiento phoney contra el cual se rebelaba Holden. La transformación de la propia rebeldía 
en conformismo, la automixtificación convertida en «autenticidad», así como la transición que no lleva a ninguna parte, son algunos de los síntomas psicosociales presentados fríamente por la novela de Fuguet.

Al declarar que «Ni la perfección ni la madurez están entre mis metas» el héroe fuguetiano da voz a la desaparición total del Bildung del horizonte axiológico social y rompe al mismo tiempo con la tradición romántica en la cual, no obstante, la novela se inscribe temáticamente. La propia construcción paratáctica de la novela chilena refleja este estancamiento en una transición sin meta, imagen distópica de una entera sociedad, como la chilena en la última década del siglo XX, que se hunde en cinismo, autocomplaciencia y nihilismo barato, propio del das Man. Se entiende así que el breve destello de un neorromanticismo a medidados del siglo XX, cuyo aliciente todavía refulge en la imprecisa búsqueda de Holden Caufield y de Edgar Wibeau, se ha convertido en ceniza en el Chile postpinochetista y que la novela de Fuguet indaga el cariz nefando de la adolescencia, vista como edad de la insubordinación gratuita y la completa irresponsabilidad, para revelar el callejón sin salida no solo de un país latinoamericano sino del entero Occidente sumido en el letargo consumista y (sórdidamente) hedonista.

\section{REFERENCIAS BIBLIOGRÁFICAS}

Doctorow 2010: El Doctorow. «Authors' tributes: 'His great theme was the moral rootlessness of American life'». The Guardian. 29.01.2010. [http://www.theguardian.com/books/2010/jan/29/jd-salingertribute] Web. 28/02/2016.

Fuguet 2011 [1991]: Alberto Fuguet. Mala onda, Providencia / Santiago de Chile: Aguilar Chilena Ediciones S.A.

Goethe 1997: Johann Wolfgang Goethe. Werther, traducción de José Valor, Madrid / México / Buenos Aires / Santiago / Miami: Edaf.

Haugrud Reiff 2008: Raychel Haugrud Reiff. J. D. Sallinger, New York: Marshall Cavendish Bencham.

Jäger 1984: Georg Jäger. «Ein Werther der DDR - Plenzdorfs Neue Leiden des jungen $W$ im gespaltenen Deutschland». Georg Jäger, Die Leiden des alten und neuen Werther (Literatur-Kommentare 21), München: Carl Hanser, 45-56.

Lee 1990: A. Robert Lee. «Flunking Everything Else Except English Anyway: Holden Caulfield, Author». Joel Salzberg, Critical Essays on Salinger's The Catcher in the Rye. Boston, Hall, 185-197. 
Lerner \& Steinberg 2004: Richard M. Lerner \& Laurence D. Steinberg. Handbook of Adolescent Psychology. ( $2^{\text {nd }}$ ed.) Hoboken, New Jersey: John Wiley \& Sons.

McCort 1997: Dennis McCort. «Hyakujo's Geese, Amban's Doughnuts, and Rilke's Carrousel: Sources East and West for Salinger's Catcher», Comparative Literature Studies, 34/3, The Pennsylvania State University, 260-278.

Miller 1982: Edwin Haviland Miller. «In Memoriam: Allie Caulfield», Mosaic, 1: 129-140.

Musil 2009 [1906]: Robert Musil. Las tribulaciones del estudiante Törless. Traducción de Roberto Bixio. Barcelona: Seix Barral.

Nemrava \& Rosso 2014: Daniel Nemrava \& Ezequiel de Rosso. Entre la experiencia y la narración: Ficciones latinoamericanas de fin de siglo (1970-2000). Madrid: Verbum.

Neubert 1973: Werner Neubert. «Niete in Hosen - oder...?» En Neue Deutsche Literatur, 21: 130-135.

Nieves Alonso 2004: María Nieves Alonso. «Alberto Fuguet, un (in)digno descendiente de una buena tradición». Acta Literaria, 29: 7-31, [https://scielo.conicyt.cl/scielo.php?script=sci_ abstract\&pid=S0717-68482004002900002\&lng=es\&nrm=iso] Web. 28/02/2020.

Pasco 1997: Allan H. Pasco. Sick Heroes. French Society and Literature in the Romantic Age, 1750-1850. Exter: University of Exter.

Plenzdorf 1984 [1972]: Ulrich Plenzdorf. Las nuevas cuitas de W: un Werther en pantalón vaquero, traducción de Marisa Delgado, Madrid: Alfaguara.

Riesman 1950: David Riesman. The Lonely Crowd: A Study of the Changing American Character, USA: Yale University Press.

Rojo 2011: Grínor Rojo. «"Mala onda", "lata" e "ironía" en Mala onda de Alberto Fuguet». América sin nombre, 16: 181-192.

Salinger 1990 [1963]: Jerome David Salinger. Seymour: Una introducción, traducción de Carmen Criado, Barcelona / Buenos Aires: Edhasa.

Salinger 1995 [1951]: Jerome David Salinger. El guardián entre el centeno, traducción de Carmen Criado. Madrid: Alianza Editorial.

Salinger 2018 [1951]: Jerome David Salinger. The Catcher in the Rye, London: Penguin.

Stayton 1985: Richard Stayton. «Required Reading: Why Holden Caulfield Still Catches You». Herald Examiner, 12 de octubre de 1985: 35.

Waiblinger 1976: Franz Peter Waiblinger. «Zitierte Kritik. Zu den WertherZitaten in Ulrich Plenzdorfs Die neuen Leiden des jungen W.», Poetica, 8: 71-88. 
THREE NOVELS OF TEENAGERS: SALINGER, PLENZDORF, FUGUET

\section{Summary}

The purpose of this article is to analyse the novel Mala onda (1991), written by the Chilean Alberto Fuguet, from a comparactive perspective that demostrates the novel's belonging to the young adult novels, particularly to those novels that have a strong intertextual connection with J. D. Salinger's The Catcher in the Rye. To highlight its specific characteristics withing this group, the book will be compared on the one hand, with its North American counterpart, and on the other hand, with a similar German novel, Ulrich Plenzdorf's Die neue leiden des jungen $W$. (Las nuevas cuitas del joven $W$. 1972). What we will emphasise will be the escalation of pesimism and even of cinism, as well as the sharpening of the political awareness over the years. All these features are also connected with a subtle separation of the narrator's perspective and that of the implied author, in the context of a common first person narrative. Through these three novels we can observe the transformation of values and of the life ideals in the Occidental society during the last seventy years.

Keywords: Young adult novels, literature and politics, J. D. Salinger, Ulrich Plenzdorf, Alberto Fuguet. 